\title{
Patient Satisfaction Survey in Inpatients of a Tertiary care Teaching Hospital
}

\author{
Dr M V Rao ${ }^{1}$, Dr DayakarThota ${ }^{2}$, Dr P Srinivas ${ }^{3}$,Dr Jaya Kumar C D ${ }^{3}$ \\ ${ }^{1}$ Associate Professor, ${ }^{2}$ Professor\& Head of the department, ${ }^{3}$ Senior Resident \\ Department of Hospital Administration, Kamineni institute of Medical Sciences, Narketpally, TS, India
}

\begin{abstract}
With the ever changing health care scenario demanding highest of quality care coupled with high expectations of patients to have their needs well satisfied when they visit a health care provider, there is an imminent need for every hospital to be aware of the demand and make all out efforts, to meet them, in order to remain as an active player in the field. Patients expect to be satisfied not only by the quality of health care they receive, but also fulfillment of their needs at all service areas of a health care institution where ever they require to interact. Keeping with the vision of the institution, to provide always the best of patient care to its clientele, a patient satisfaction survey in inpatients of a tertiary care teaching hospital has been carried out. Methodology adopted was to capture responses of a sample of patients, on a structured questionnaire, covering various dimensions of patient satisfaction. Patients' ratings and suggestions showed that while the quality of medical and nursing care has adequately satisfied them, the ancillary services of the hospital, such as the environment, meal service, billing and pharmacy, seemed to be wanting in meeting the desired satisfaction levels and thus rendering them the focus areas for improvement. Patient satisfaction survey is a valuable tool to measure the outcomes of quality care rendered by a health care institution. Meeting the patient needs and expectations at every service transaction, not only indicates the quality of care delivered but also is vital to the institution's reputation and its sustenance through competitive environment.
\end{abstract}

Keywords: Patient satisfaction, Patient Centered Care, Quality

\section{Introduction}

Health care is changing rapidly and the need to improve quality in healthcare delivery is increasing. Hospitals need to show the community that they are interested in quality care, and they need to find ways to improve that, in order to remain competitive. Patient satisfaction is a key determinant of quality of care and an important component of pay-for-performance metrics. It is a central indicator for healthcare quality and reflects the ability of the provider to meet the patients' needs. Patients are easier to serve if they feel their needs are being met. Conversely, when the needs are not met, the dissatisfaction manifests through adverse reactions from them. In the ideal service environment, meeting just the needs may not be enough but; the provider would want to delight the customer ${ }^{1}$. Defined in any number of ways, Patient satisfaction, it is often publicly reported, helps patients choose among health care providers ${ }^{2}$.

\subsection{Why patients need to be satisfied:}

Research has identified a clear link between patient outcomes and patient satisfaction scores1 .Keeping patients satisfied has many proven benefits. Satisfied patients are more likely to adhere to prescribed treatment plans, maintain an ongoing relationship with a health care provider and realize subsequent benefits relating to health outcomes. Provider's interests are also well served by satisfied patients, and may realize improved volume related to community reputation, reduced malpractice claims, more satisfied staff and related decreased turnover, and improved efficiency ${ }^{2}$. Satisfied patients are more likely, than the unsatisfied ones, to continue using the health care services, maintaining their relationships with specific health care providers and complying with the care regimens ${ }^{3}$.

\subsection{Patient Centered Care and Patient Engagement:}

Patients carry certain expectations before their visit and the resultant satisfaction or dissatisfaction is the outcome of their actual experience ${ }^{4}$.It's not enough for patients to be merely satisfied with their health care. Care assessed to be of high quality as per any provider-defined criteria is not ideal if the patient feels dissatisfied. Expectations and perceptions of the patient experience vary widely, and the ultimate outcome shall be the care that is patient-centered. Patient-centered care requires patient engagement and active participation in disease management ${ }^{2}$. Patient-centered care can improve treatment outcomes; Patients' satisfaction with care is one of the pillars of patient-centered care ${ }^{5}$. 


\subsection{Patient Satisfaction and Quality Nursing Care:}

A very important aspect on which patient satisfaction depends is nursing care, because nurses are involved in almost every aspect of client's care in hospital ${ }^{6}$. Higher level of patience and use of appropriate communication skills may increase patients' level of satisfaction towards nursing care, and these also help the nurses to be more satisfied in their work ${ }^{7}$.Examining the items with low patient satisfaction, will enable nurses to identify the defects in nursing care and institute appropriate change. Patient assessment surveys should be carried out routinely by health institution in all aspects of nursing care to improve the quality of service ${ }^{8}$.

\subsection{Patient Satisfaction is multidimensional:}

Patient satisfaction is a multidimensional construct that reflects the type and quality of service provided by healthcare providers, how well it is delivered, and the extent to which the expectations and needs of patients are met ${ }^{9}$. Patients distinguish and evaluate distinct episodes of a health care experience. Application of this concept to the inpatients means that patients experience and evaluate the quality of care and service provided when admitted, when undergoing tests and treatment procedures, care by nurses and physicians throughout the stay, the meal service, the discharge process, and many more factors. Hence, it is considered inappropriate to report and analyze only overall satisfaction, without considering patients' satisfaction with the multiple dimensions of a health care experience ${ }^{10}$.

\section{5. Measuring Patient Satisfaction:}

Factors associated with satisfaction are thought to include the structure, process and outcome of care as well as patient's socio-demographic, physical and psychological status, attitudes and expectations concerning medical care. Quality assessment studies generally measure one of three types of outcome: medical outcomes, costs, and client satisfaction. For the last mentioned, clients are asked to assess not their own health status after receiving care but their satisfaction with the services delivered ${ }^{11}$.

\subsection{Eliciting Ratings of Care:}

Patient based surveys adopt a variety of approaches to elicit overall ratings of care. Standard questions and set of responses and supplementary questions related to overall aspects of care, and to cover dimensions of patient satisfaction could be a good model to adopt ${ }^{12}$.

\section{Methods}

2.1 Study Design: A survey through a customized questionnaire, of an identified sample of inpatients in different patient care areas, to obtain their responses to question items standardized on various dimensions of care. The questionnaire consists of two parts:

Part I: Items, capturing demographic details of the sample patients

Part II: Items covering dimensions of attributes representing the services through which the patients transacted.

The responses were rated on a three point scale based on Likert's scale of measurement.

2. 2 Sample Size: A sample of 160 inpatients was taken, based on the average inpatient statistics.

2. 3 Data Collection and Compilation: One survey team of ten members, drawn from Post graduate courses of Medicine and Nursing, duly oriented to the process, have served the questionnaire to the sample inpatients, captured their responses and compiled the data. Out of a total of 160 responses, 149 valid responses were taken for analysis, using MS Excel.

\section{Results and Discussions}

Analysis of the responses included (a) profile of the responders :( Table I \& Figure I), rating of service wise attributes: (Table II \& Figure II, a \& b), responses to open ended questions:

(a)What patients liked most in services, (b) Service wise suggestions for improvement.

While the tables depict the results in absolute numbers; the figures represent percentile. The results of analysis are discussed with respective tables and figures. 
Table I:Profile of the Responders

\begin{tabular}{|c|c|c|c|c|c|c|c|}
\hline Gender & Male & Female & & & & & \\
\hline & 83 & 66 & & & & & \\
\hline \multirow[t]{2}{*}{ Literacy } & $P G$ & Graduate & Intermediate & School & Illiterate & & \\
\hline & 14 & 40 & 4 & 50 & 40 & & \\
\hline \multirow[t]{2}{*}{ Occupation } & $\begin{array}{l}\text { Government } \\
\text { Job }\end{array}$ & $\begin{array}{l}\text { Private } \\
\text { Job }\end{array}$ & Business & Farmer & $\begin{array}{l}\text { Daily } \\
\text { Wage }\end{array}$ & $\begin{array}{l}\text { House } \\
\text { wife }\end{array}$ & Student \\
\hline & 40 & 21 & 8 & 7 & 13 & 42 & 9 \\
\hline \multirow[t]{2}{*}{$\begin{array}{l}\text { Referred } \\
\text { by }\end{array}$} & Doctor & Friend & Media & $\begin{array}{l}\text { Direct } \\
\text { Walk-in }\end{array}$ & & & \\
\hline & 72 & 38 & 3 & 36 & & & \\
\hline \multirow[t]{2}{*}{$\begin{array}{l}\text { Health } \\
\text { Condition } \\
\text { after } \\
\text { treatment }\end{array}$} & Improved & Same & Worsened & $\begin{array}{l}\text { First } \\
\text { visit }\end{array}$ & & & \\
\hline & 131 & 11 & 0 & 7 & & & \\
\hline
\end{tabular}

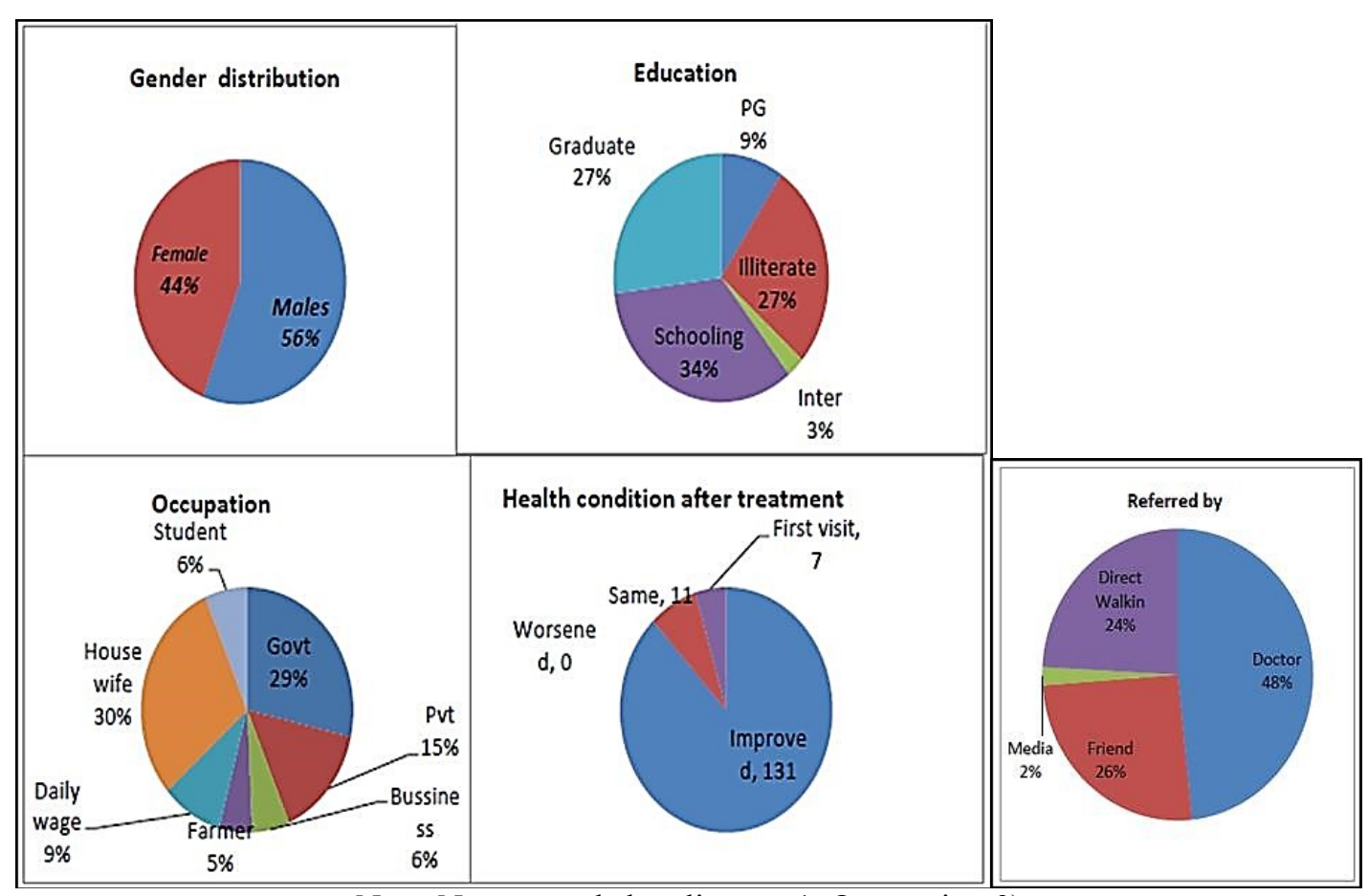

Note: Not responded to: literacy-1, Occupation-9)

Figure I: Profile of the Responders: Gender distribution, Males -56\%, Females - 44\%; Literacy - Post Graduates - $9 \%$, Graduates- $27 \%$, Intermediate-3\%, up to schooling -34\% and Illiterates-27\%;Occupation House wives- $30 \%$, Govt. job- $29 \%$, Pvt Jobs- $15 \%$, daily wage workers- $9 \%$, business- $6 \%$, students- $6 \%$, farmers- $5 \%$; Health condition after treatment- Improved- $88 \%$, same- $7.3 \%, 4.7 \%$ could not comment, being on their first visit. 
Table II: Rating of Service wise attributes $n=149$

\begin{tabular}{|l|l|l|l|l|}
\hline Attribute & Poor & Average & Good & Blank \\
\hline Admission process & 5 & 24 & 120 & 0 \\
\hline Transfer to ward & 1 & 24 & 124 & 0 \\
\hline Receiving in ward & 3 & 39 & 107 & 0 \\
\hline Responsiveness of staff & 0 & 40 & 109 & 0 \\
\hline Meals Services & 7 & 46 & 91 & 05 \\
\hline Discharge & 1 & 45 & 99 & 04 \\
\hline Doctor consultation & 2 & 8 & 138 & 01 \\
\hline Nursing care & 2 & 22 & 124 & 01 \\
\hline Laboratory & 6 & 48 & 81 & 14 \\
\hline Imageology & 2 & 47 & 77 & 23 \\
\hline Pharmacy & 2 & 37 & 87 & 23 \\
\hline Billing & 10 & 34 & 32 & 73 \\
\hline Physical Environment & \multicolumn{5}{l}{} \\
\hline Cleanliness & 5 & 28 & 116 & 0 \\
\hline Toilets & 9 & 45 & 95 & 0 \\
\hline Bed \& Patient linen & 5 & 47 & 97 & 0 \\
\hline House keeping & 5 & 32 & 110 & 02 \\
\hline
\end{tabular}

In service wise ratings, consultation with the doctors was rated good by most patients $(93 \%)$, followed by nursing care( $84 \%$ ).Admission process, transfers to ward, receiving in ward, responsiveness of staff were next in good ratings $(72 \%-83 \%)$ Discharge process, meals services, diagnostic services, Imageology, and pharmacy were rated good by $60 \%$ to $69 \%$ of respondents. Physical environment, cleanliness, housekeeping, Bed \&patient linen received good rating from $65 \%$ to $78 \%$ patients. Billing related issues attracted poor satisfaction levels as it topped in the poor rating by most $(13 \%)$.

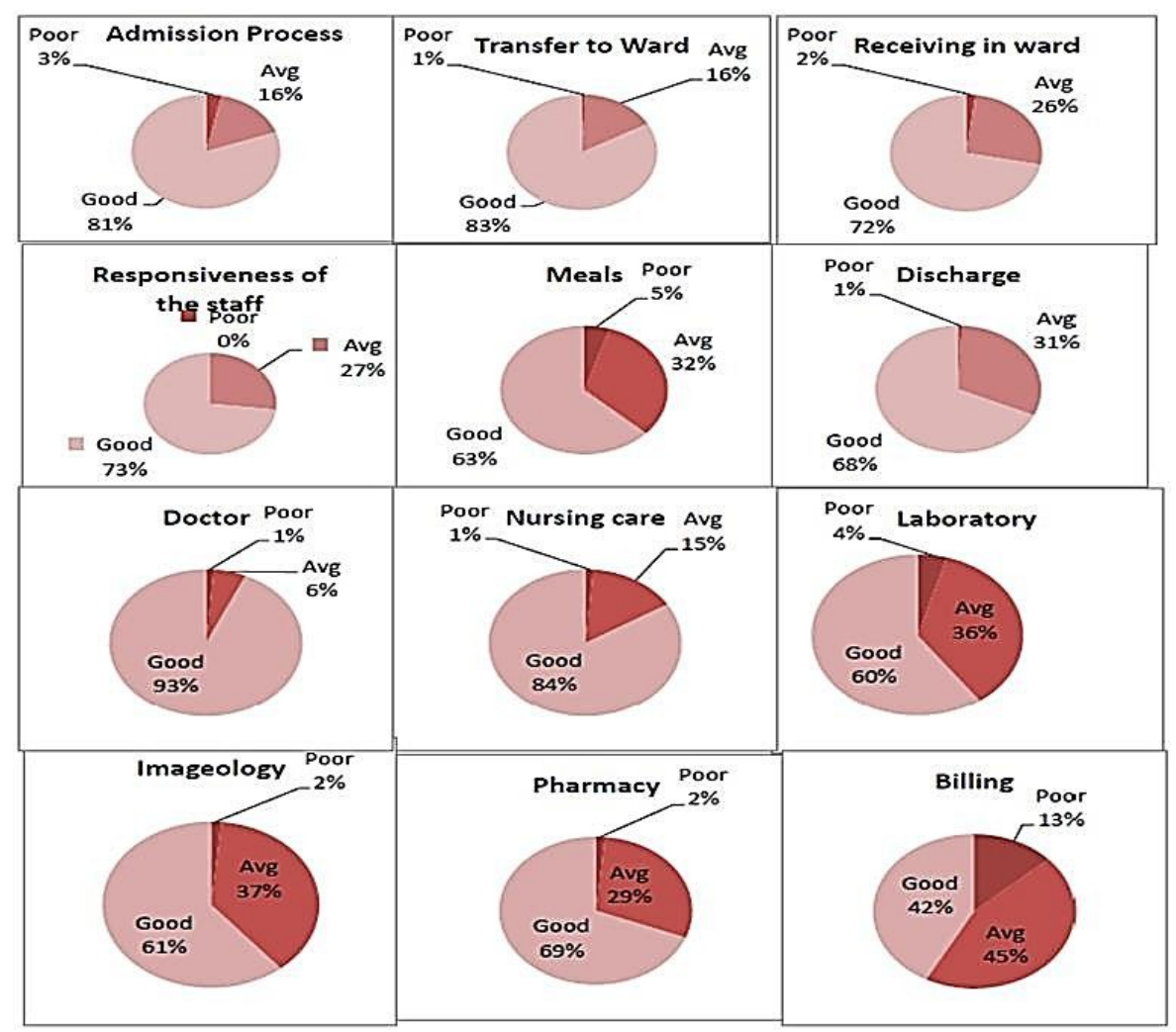

Figure-II (a) Service attributes: 


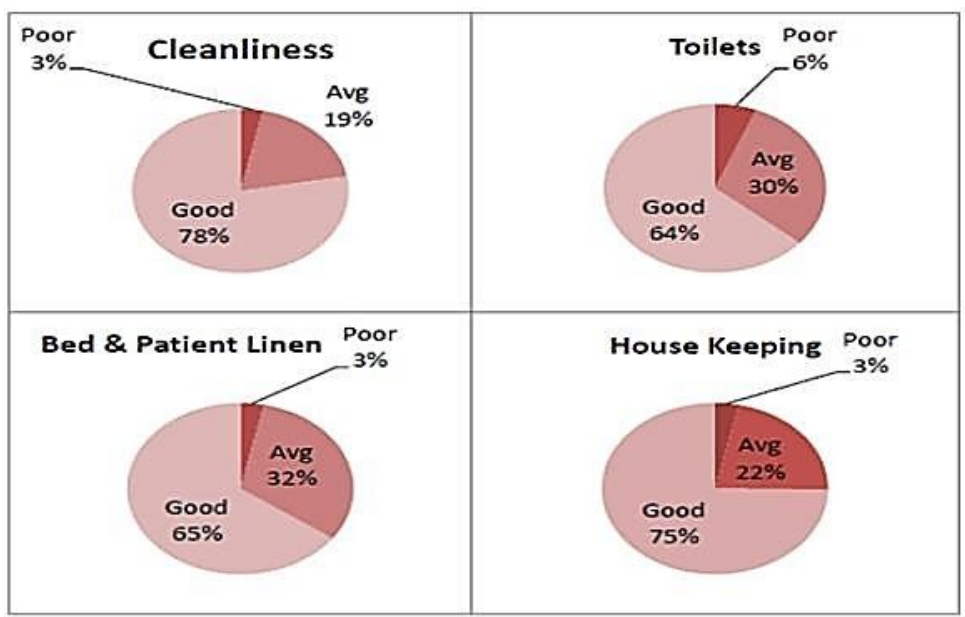

Figure-II (b) Physical environment:

\section{Responses to Open ended Questions:}

(a) What patients liked most in services?

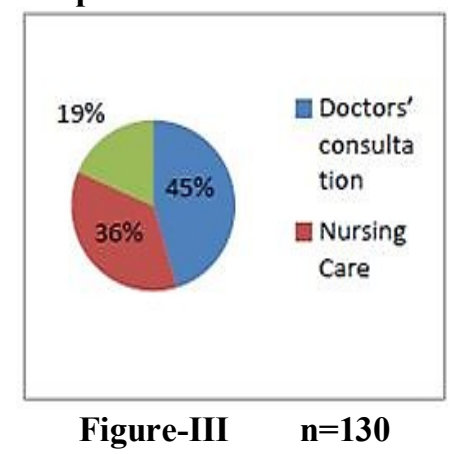

Out of total surveyed, 87 patients responded to the question, giving a response rate of $58 \%$. Multiple responses were received, making a total of 130 , which were analyzed. Asked to rate the services they liked most, the patients rated doctors' consultation at number one, followed by nursing care and then other services.

\section{(b)Service wise suggestions for improvement:}

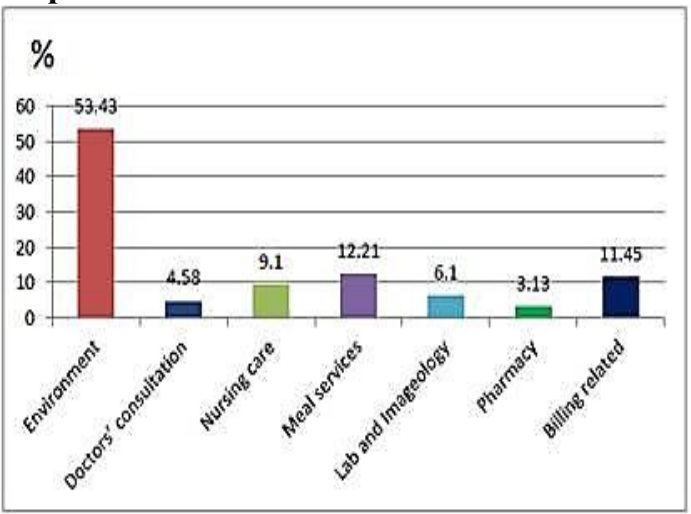

Figure-IV n=131

Out of total surveyed, 91patients responded to the question, giving a response rate of $61 \%$.Multiple responses were received, making a total of 131, which were analyzed. Most suggestions were for improvement in environment, such as general cleanliness of inpatient areas, toilets, and bed and patient linen. Improvement in meal services was next in the list of concerns, followed by billing related issues. Few responses suggested improvement in nursing care, doctor's consultation and pharmacy services. 


\section{Conclusion}

A patient satisfaction survey was carried out amongst inpatients of a tertiary care teaching hospital by using the conventional method of obtaining patients' ratings, on a questionnaire, covering various dimensions of patient satisfaction. The survey results showed that most patients were satisfied with the medical and nursing care, but their expectations from the general facilities and ancillary services such as environment, meal services, waiting time issues were not adequately met and hence were rated low on satisfaction levels. Their suggestions for improvement also pointed to those areas of service.

Patient satisfaction survey is a valuable tool to measure the outcomes of quality care rendered by a health care institution. Meeting the patient needs and expectations at every service transaction, not only indicates the quality of care delivered but also is vital to the institution's reputation and its sustenance through competitive environment. The surveys, based on patients' ratings of the services received by them, enable the providers to identify areas for interventions towards continued quality enhancement in care.

\section{Acknowledgements}

The authors sincerely acknowledge the cooperation and contribution of the sample patients for their valuable inputs .Authors also thank the Management and Administration of the institution, departmental staff of inpatient areas and survey team members for their support in the study.

No funding from any source has been obtained, to support this work.

\section{References}

[1] Morris, B. J., Jahangir, A. A., \& Sethi, M. K. (2013). Patient satisfaction: an emerging health policy issue. American Academy of Orthopedic Surgeons Now, 7(6).

[2] Korda, H. Patient Satisfaction: The new rules of engagement. The Health Care Blog. $\mathrm{http} / /$ thehealthcareblog.com/blog/2012/10/26/patient-satisfaction-the-new-rules-of-engagement/ (last access June 30, 2014).

[3] Al-Doghaither, Abdullah H., et al. "Patients' Satisfaction with primary health care centers services in Kuwait city, Kuwait." Journal of family \& community medicine 8.3 (2001): 59

[4] Arshad, Andrabi Syed, et al. "Measuring patient satisfaction: A cross sectional study to improve quality of care at a tertiary care hospital." Healthline, Journal of Indian Association of Preventive and Social Medicine 3.1 (2012): 59-62.

[5] Doyle, Cathal, Laura Lennox, and Derek Bell. "A systematic review of evidence on the links between patient experience and clinical safety and effectiveness." BMJ open 3.1 (2013).

[6] Samina, Mufti, et al. "Patient's perception of nursing care at a large teaching hospital in India." International journal of health sciences 2.2 (2008): 92 .

[7] Akhtari-Zavare, Mehrnoosh, et al. "Patient satisfaction: evaluating nursing care for patients hospitalized with cancer in Tehran Teaching Hospitals, Iran." Global Journal of Health Science 2.1 (2010): P117.

[8] Dzomeku, V. M, et al." IN- Patient Satisfaction with nursing care: A case study at Kwame Nkrumah University of Science and Technology Hospital". International Journal of Research in Medical and Health Sciences pp. 19 - 24 Vol 02. No. 1 - 2013

[9] Afolabi, M. O., E. R. I. Afolabi, and B. A. Faleye. "Construct validation of an instrument to measure patient satisfaction with pharmacy services in Nigerian hospitals." African health sciences 12.4 (2013): 538-544.

[10] Clark, Paul Alexander, et al. "Elderly inpatients' priorities for acute care service quality." International Journal of Health Care Quality Assurance 17.2 (2004): 92-104.

[11] Ashrafun, Laila, and Mohammad Jasim Uddin. "Factors determining inpatient satisfaction with hospital care in Bangladesh." Asian social science 7.6 (2011): p15

[12] Pearse, Jim. "Review of patient satisfaction and experience surveys conducted for public hospitals in Australia: A Research Paper for the Steering Committee for the Review of Government Service Provision." St Leonards, Australia: Health Policy Analysis Pty $\operatorname{Ltd}(2005)$ 